\title{
The Roles of ZnTe Buffer Layers on CdTe Solar Cell Performance
}

Colin A. Wolden, ${ }^{*}, 1,2$ Ali Abbas, ${ }^{3}$ Jiaojiao Li, ${ }^{2}$ David R. Diercks, ${ }^{2}$ Daniel M. Meysing, ${ }^{1,4}$ Timothy R. Ohno, ${ }^{5}$ Joseph D. Beach, ${ }^{5}$ Teresa M. Barnes, ${ }^{4}$ and John M. Walls ${ }^{3}$

${ }^{1}$ Department of Chemical and Biological Engineering, Colorado School of Mines, Golden, CO 80401, USA

${ }^{2}$ Materials Science Program, Colorado School of Mines, Golden, CO 80401

${ }^{3}$ University of Loughborough, Leicestershire LE11 3TU, United Kingdom

${ }^{4}$ National Renewable Energy Laboratory, Golden, Colorado, 80401, USA

${ }^{5}$ Department of Physics, Colorado School of Mines, Golden, CO 80401

\begin{abstract}
The use of ZnTe buffer layers at the back contact of CdTe solar cells has been credited with contributing to recent improvements in both champion cell efficiency and module stability. To better understand the controlling physical and chemical phenomena, high resolution transmission electron microscopy (HR-TEM) and atom probe tomography (APT) were used to study the evolution of the back contact region during rapid thermal processing (RTP) of this layer. After activation the ZnTe layer, initially nanocrystalline and homogenous, transforms into a bilayer structure consisting of a disordered region in contact with CdTe characterized by significant $\mathrm{Cd}$ $\mathrm{Zn}$ interdiffusion, and a nanocrystalline layer that shows evidence of grain growth and twin formation. Copper, co-evaporated uniformly within $\mathrm{ZnTe}$, is found to dramatically segregate and aggregate after RTP, either collecting near the $\mathrm{ZnTe} \mid \mathrm{Au}$ interface or forming $\mathrm{Cu}_{\mathrm{x}} \mathrm{Te}$ clusters in the CdTe layer at defects or grain boundaries near the interface. Analysis of TEM images revealed that $\mathrm{Zn}$ accumulates at the edge of these clusters, and three-dimensional APT images confirmed that these are core-shell nanostructures consisting of $\mathrm{Cu}_{1.4} \mathrm{Te}$ clusters encased in $\mathrm{Zn}$. These changes in morphology and composition are related to cell performance and stability.
\end{abstract}

Keywords: CdTe, ZnTe, TEM, APT, copper telluride

* Corresponding author. E-mail address: cwolden@ mines.edu 


\section{Introduction}

With an ideal band gap $(\sim 1.45 \mathrm{eV})$ and large absorption coefficient $\left(>10^{4} \mathrm{~cm}^{-1}\right)$ CdTe has emerged as the leading thin-film photovoltaic (PV) technology with record device efficiency currently at $21.5 \%$ [1]. Most recent advances have been due to improvements in short circuit current $\left(\mathrm{J}_{\mathrm{sc}}\right)$ and fill factor $(\mathrm{FF})$, whereas the open circuit voltage $\left(\mathrm{V}_{\mathrm{oc}}\right)$ values have remained largely unchanged [2]. A requirement for high $\mathrm{V}_{\text {oc }}$ is good ohmic contact with $\mathrm{CdTe}$, which is challenging due to its low doping and high work function. Consequences of such barriers include loss of open circuit voltage $\left(\mathrm{V}_{\mathrm{oc}}\right)$ and fill factor $(\mathrm{FF})$, which are often manifested by the presence of roll over behavior in J-V curves [3]. A common strategy to address this problem is through the insertion of a thin interfacial layer between the CdTe and metal contact [4]. Copper-doped zinc telluride $(\mathrm{ZnTe}: \mathrm{Cu})$ has been widely adopted for this role [5]. Copper degenerately dopes this layer, which narrows the barrier width and permits electron tunneling, creating a quasi-ohmic contact [6]. Copper has been associated with several defect states located within the CdTe band gap [7]. some of which have been implicated to contributing to reduced carrier lifetime and/or problems with stability [8]. First Solar Inc. recently reported that they have integrated ZnTe buffer layers into their commercial modules [9]. Incorporation of ZnTe has been credited with improving champion device efficiency as well as enhancing both the stability and temperature sensitivity of their modules. In this paper we provide nanoscale characterization of the back contact region that provides new insights into the mechanism(s) that may contribute to these improvements.

We recently introduced a back contact procedure in which $\mathrm{ZnTe}: \mathrm{Cu}$ is co-evaporated at low temperature followed by activation using rapid thermal processing (RTP).[10, 11] RTP offers several advantages for this activation step including improved control, low thermal budget, and 
high throughput. This technique has been used in the fabrication of CdTe solar cells on flexible glass with certified efficiencies of $16.4 \%$.[12] Previously the macroscopic distribution of $\mathrm{Cu}$ was characterized using secondary ion mass spectrometry (SIMS) both before and after RTP processing [10], and quantitative analysis of this data raised a number of important questions. First, the optimal dose of $\mathrm{Cu}$ in the as-deposited $\mathrm{ZnTe}: \mathrm{Cu}$ is $\mathrm{Q}_{0} \sim 10^{17} \mathrm{~cm}^{-2}$, which is about two orders of magnitude greater than the optimal amount required for doping CdTe as reported by Kranz et al. [13], and about an order of magnitude greater than the few nms of copper that is typically used to form $\mathrm{Cu}_{\mathrm{x}} \mathrm{Te}$-based contacts $[14,15]$. In fitting the $\mathrm{Cu}$ diffusion profiles in $\mathrm{CdTe}$ as a function of RTP temperature the modeled dose was reduced to $20 \%$ of the experimental value in order to obtain good agreement with the SIMS data [10], which implies that the majority of the $\mathrm{Cu}$ supplied during co-evaporation does not enter the absorber layer. Lastly, the effective diffusivity of $\mathrm{Cu}$ extracted from the SIMS profiles was just $\sim 10^{-12} \mathrm{~cm}^{2} / \mathrm{s}$, which is three to five orders of magnitude less than values expected at the temperatures involved $[16,17]$.

One limitation of SIMS is that it provides averaged one-dimensional profiles, and does not account for any lateral variations that may be present. In polycrystalline $\mathrm{CdTe}$, it is well known that impurities such as $\mathrm{Cu}$ are preferentially transported and accumulated along grain boundaries [18]. Understanding the nanoscale distribution of these elements is critical to advancing the fundamental understanding of this material system. To this end we employ atom probe tomography (APT) and high-resolution transmission electron microscopy (HR-TEM) to quantify the changes in structure and composition in the back contact region of $\mathrm{ZnTe}: \mathrm{Cu}$ contacted solar cells during RTP activation. 


\section{Materials and Methods}

\subsection{Device Fabrication}

Figure 1 displays a schematic cross-section of the superstrate architecture employed by the devices examined in this work. The front contacts employ a tin oxide bilayer deposited on Corning 7059 glass by thermal chemical vapor deposition followed by an oxygenated CdS:O window layer deposited by reactive sputtering as described in the literature [19]. The only difference in the two sets of devices examined was the nature of the CdTe absorber layer. One set of devices employed CdTe deposited by close space sublimation (CSS) at $600{ }^{\circ} \mathrm{C}$ at the National Renewable Energy Laboratory (NREL) [19]. The second set of devices was fabricated at Colorado School of Mines (CSM) by vapor transport deposition (VTD) at $450{ }^{\circ} \mathrm{C}$ [20]. In both cases the devices were completed at CSM. Back contact preparation involved a $10 \mathrm{~s}$ dip in a 0.05 vol. \% bromine methanol solution to remove oxides and surface contaminants introduced during vapor $\mathrm{CdCl}_{2}$ treatment. Afterwards $\sim 165 \mathrm{~nm}$ of $\mathrm{ZnTe}: \mathrm{Cu}(\sim 4 \mathrm{wt} . \% \mathrm{Cu})$ was evaporated by co-evaporation, followed by evaporation of $\sim 100 \mathrm{~nm}$ of Au which served as the metallization layer. Activation of the back contact was accomplished by annealing the devices in an RTP furnace for $30 \mathrm{~s}$ at the desired temperature set-point, which was measured by a thermocouple in contact with the AlN susceptor as described previously [11]. 


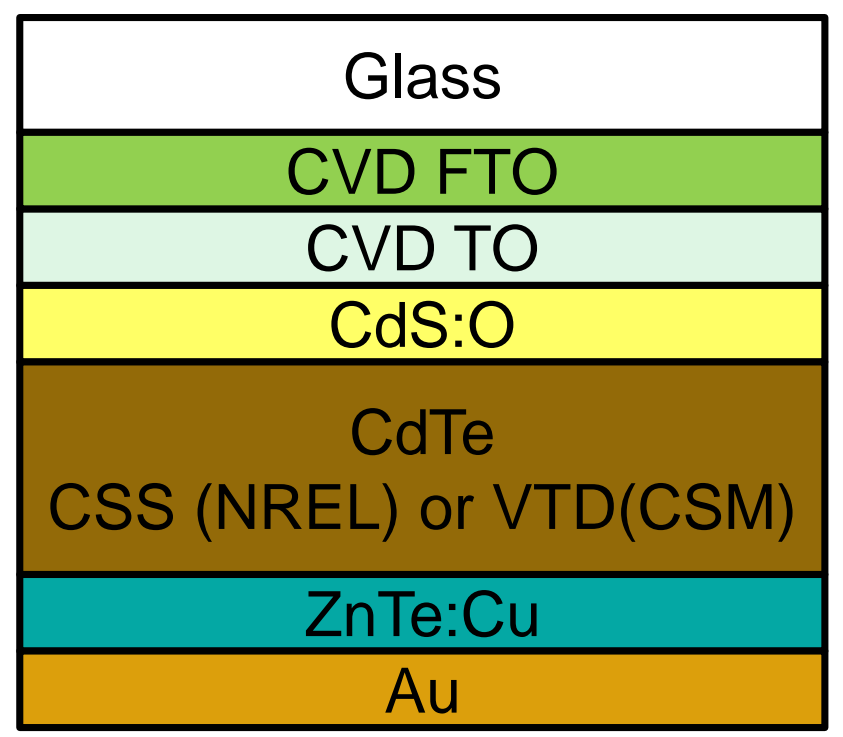

Figure 1. Schematic cross-section of the device structures considered in this work. NREL absorbers were deposited by CSS at $600{ }^{\circ} \mathrm{C}$ while CSM absorbers were deposited by VTD at 450 ${ }^{\circ} \mathrm{C}$.

\subsection{Device Performance}

The solar cell performance was measured under simulated AM1.5 radiation using a commercial tool that is calibrated using a certified silicon standard (PV Measurements). Figure 2 displays the evolution of the $\mathrm{J}-\mathrm{V}$ behavior of these devices as a function of RTP annealing temperature. The CSS devices have very low efficiency $(<2 \%)$ after application of the back contact. RTP activation leads to monotonic increases in all three contributors to efficiency $\left(\mathrm{V}_{\mathrm{oc}}\right.$, $\mathrm{FF}$, and $\mathrm{J}_{\mathrm{sc}}$ ) up until the optimal temperature which was $300{ }^{\circ} \mathrm{C}$. In contrast, the devices fabricated at CSM display strong current collection prior to RTP activation. Application of an optimal RTP treatment increases $\mathrm{V}_{\mathrm{oc}}$ and FF without altering $\mathrm{J}_{\mathrm{sc}}$. The application of excessive heat treatment reduced efficiency through a decline in all secondary parameters, and was correlated with an increased density of $\mathrm{Cu}$-related defects [7]. 

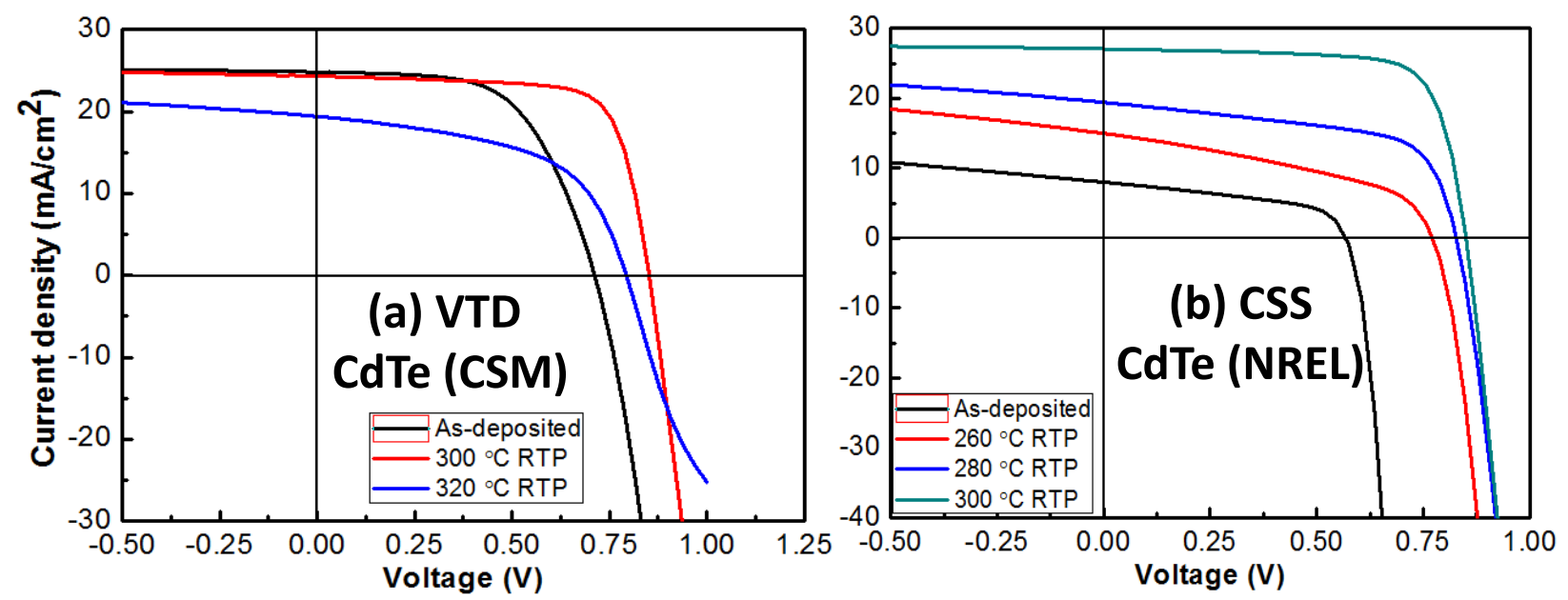

Figure 2. Evolution of J-V performance as a function of RTP treatment temperature for devices employing (a) CSM VTD CdTe and (b) NREL CSS CdTe.

The reasons for the strikingly different $\mathrm{J}-\mathrm{V}$ evolution profiles is not fully understood. Impurities are one possibility, though the CdTe source materials used in both VTD and CSS processes had nominally identical purity (>99.999\%). Another factor might be the different temperatures used, but the most plausible explanation is the presence of oxygen (6.25\%) used during CSS deposition. It has been shown that oxygen can oxidize grain boundaries and inhibit interlayer diffusion [21,22]. It is postulated that the oxidized grain boundaries may limit the effective conductivity of CSS-deposited CdTe prior to RTP activation. Despite the differences prior to RTP activation, the J-V characteristics of optimally processed devices exhibit very similar performance, with typical power conversion efficiencies of $15-16 \%$ on both platforms. To understand the changes that occur during activation nanoscale characterization of the back contact region is compared before and after RTP activation.

\subsection{Nanoscale Characterization}

Two techniques were employed to provide nanoscale characterization of structure and composition in the back contact region. High resolution transmission electron microscopy (HRTEM) was the tool used to investigate the detailed microstructure of the NREL CSS cells using the facilities at Loughborough. TEM samples were prepared by focused ion beam (FIB) milling using a dual beam FEI Nova 600 nanolab. A standard in situ lift out method described previously 
[23] was employed for sample preparation. High resolution TEM imaging was carried out in a FEI Tecnai F20 equipped with an Oxford Instruments X-Max 80 silicon drift detector (SDD) energy dispersive X-ray detector (EDX). EDX was used to produce chemical distribution maps of the cells as well as line scans and point analysis for quantitative elemental analysis. Devices fabricated at CSM by VTD were examined using atom probe tomography (APT). APT analyses were performed on a Cameca LEAP 4000X Si local electrode atom probe instrument using parameters optimized for quantitative evaluation of these materials [24]. Additionally, transmission electron microscopy (TEM) images before and after APT analyses were acquired with a Philips CM200 TEM using a holder specifically designed for imaging APT specimens [25]. 


\section{Results}

\subsection{High Resolution Transmission Electron Microscopy}

\subsubsection{Microstructure and Morphology}

First we examine the changes that occur upon RTP activation using NREL CSS absorbers. Figure 3 displays HR-TEM images of the back contact region before and after optimal RTP activation, respectively. The before image is a high-angle annular dark-field (HAADF) image of the back contact region in which the gold contact appears bright, and the Pt was introduced during sample preparation. The image contains two large CdTe grains, with a well-defined $\mathrm{ZnTe}$ layer between the absorber and the gold. The individual layers are well defined with little evidence of intermixing, as expected for the low temperature co-evaporation process. As previously reported [26] the as-deposited $\mathrm{ZnTe:Cu}$ film is nanocrystalline, and consistent with literature [27], $\mathrm{Cu}_{\mathrm{x}} \mathrm{Te}$ phases are observed to form during low temperature co-evaporation. Specifically, XRD revealed peaks at $2 \theta$ values of $24.7^{\circ}$ and $26.7^{\circ}$ that have been assigned to the (009) reflection of $\mathrm{Cu}_{2} \mathrm{Te}$ and the (101) planes of $\mathrm{Cu}_{1.4} \mathrm{Te}$, respectively [28]. 

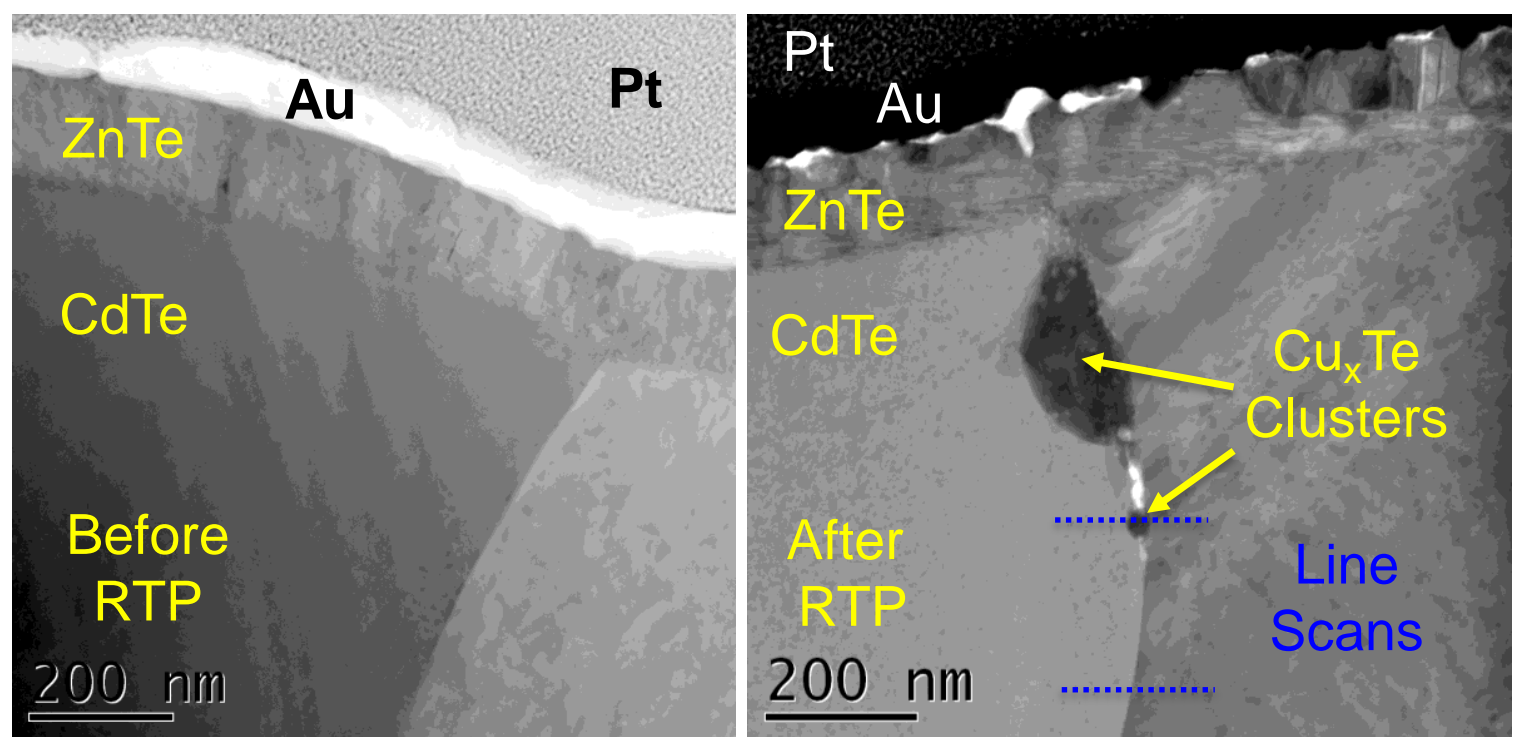

Figure 3. HAADF image (left) and a bright field TEM image (right) of the back contact region before (left) and after (right) RTP treatment. The dashed lines indicate the positions where the 1D compositional profiles shown in Figure 7 were taken.

The contrast is reversed in the bright field TEM image of the back contact after RTP activation, with heavy elements such as Au and Pt appearing dark. The ZnTe thickness remains nominally unchanged after RTP activation, but there are substantial changes to its morphology. Substantial grain growth occurs and twins not unlike those seen in CdTe are observed, particularly in the region adjacent to the gold metallization layer. In contrast, the region adjacent to the CdTe layer appears to be much more disordered, and it is suggested that the cause may be Zn-Cd interdiffusion. The CdTe grain boundary (GB) before activation appears very clean, but after activation, defects appear in the GB near the ZnTe interface. Most notable in Fig. $3 b$ is the presence of two dark clusters, one large and one small. As discussed below these clusters are $\mathrm{Cu}_{\mathrm{x}} \mathrm{Te}$, and such clusters are observed at GBs and defects in the CdTe near the interface with ZnTe. Note that after moving a few hundred nanometers from the ZnTe interface the GBs appear to be very clean and defect free. Figure 4 displays a high resolution image of the CdTe|ZnTe interface after RTP activation as well as selected area diffraction (SAD) images obtained from the two 

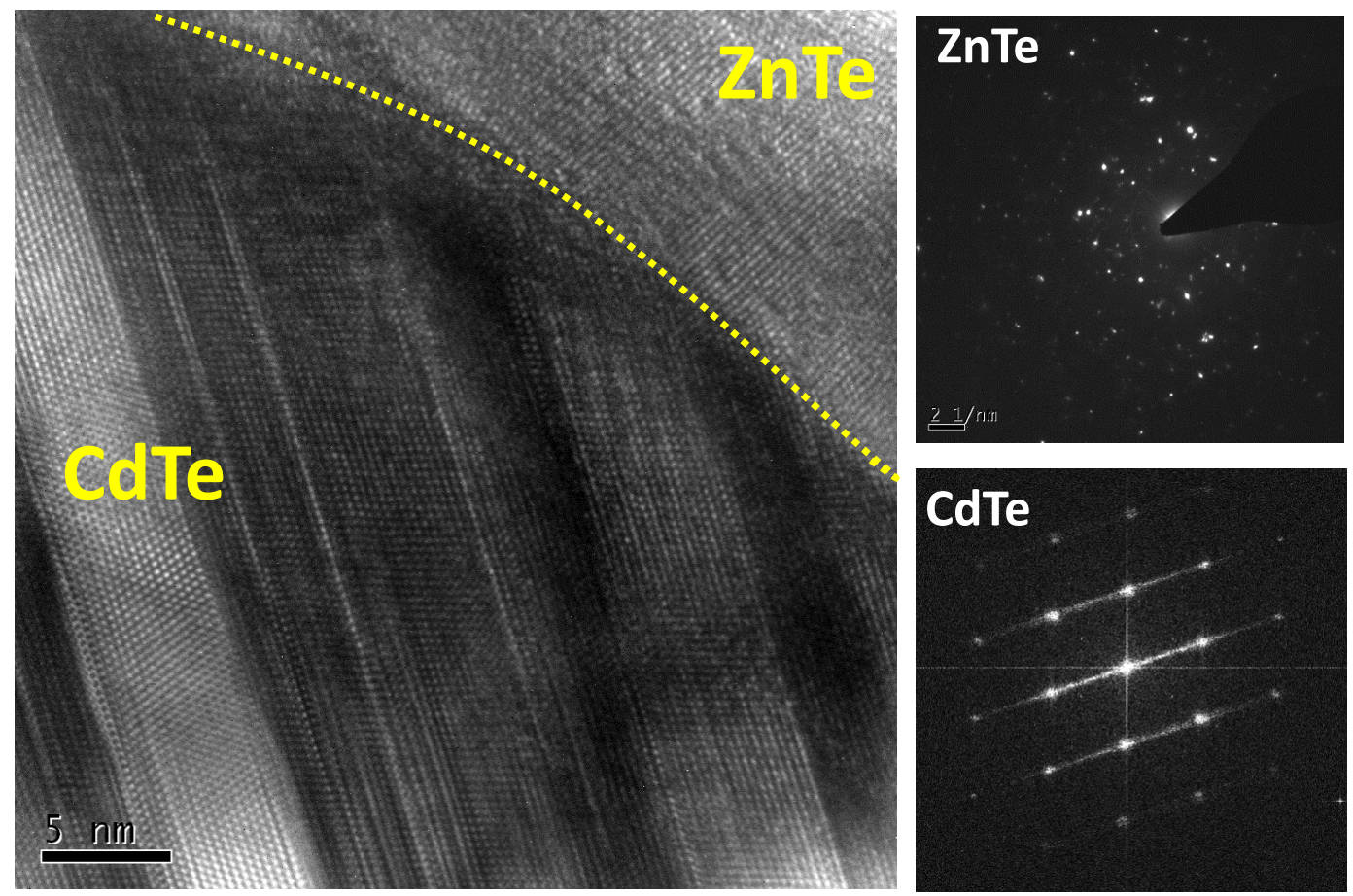

Figure 4. High resolution TEM of the CdTe|ZnTe interfacial region after RTP activation and selected area diffraction images taken from both layers.

regions. The interface is not atomically abrupt, and its approximate position is indicated by the dashed line in the TEM image. Despite disordered material along the interface, which ranged in thickness from $5-15 \mathrm{~nm}$, lattice fringes may be clearly observed within the ZnTe layer, and the nanocrystalline nature of the film is confirmed by the SAD image. Note that the diameter of the SAD aperture was comparable to the ZnTe thickness, and though it was focused on center of the ZnTe layer contributions from either $\mathrm{Au}$ or $\mathrm{CdTe}$ cannot be ruled out, making quantitative analysis challenging. In clear contrast, the large CdTe grains provide a clean SAD image characteristic of its zinc blend structure. 


\subsubsection{Back Contact Composition}

Figure 5 displays TEM images and elemental contour maps obtained from these regions before and after RTP activation, respectively. As expected, the co-evaporation process distributes the copper uniformly throughout the ZnTe layer. There is no evidence of intermixing with the exception of a small amount of $\mathrm{Cu}$ that appears to penetrate a grain boundary located at the knee

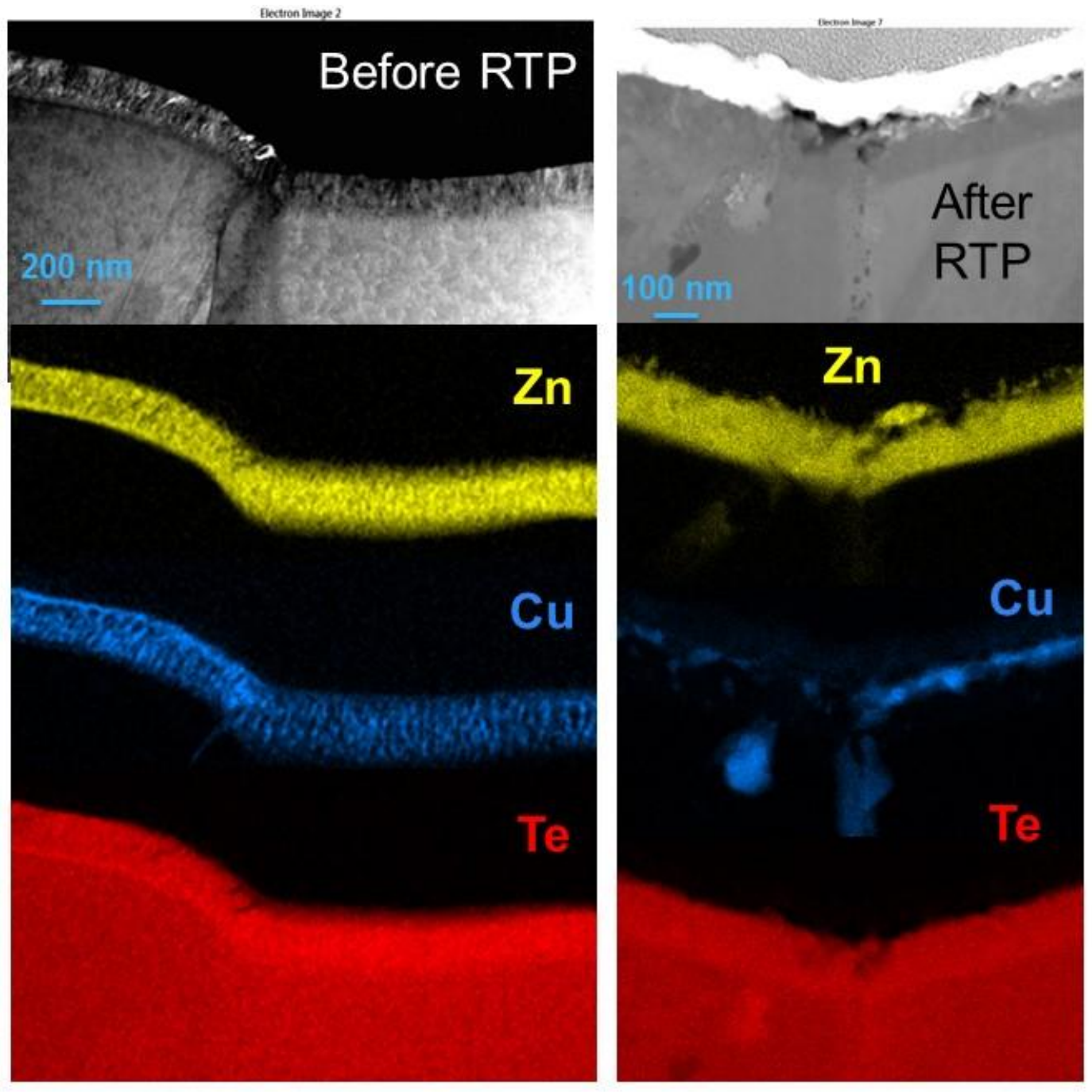

Figure 5. TEM images and elemental mapping of the back contact region before and after optimal RTP treatment. 
in the profile map. After RTP activation there are substantial changes in the elemental distribution, particularly for $\mathrm{Cu}$. The copper distribution is observed to both segregate and aggregate in dramatic fashion after RTP. The majority of the $\mathrm{Cu}$ segregates to the $\mathrm{Au} \mid \mathrm{ZnTe}$ interface, with much of it present in clusters whose size is on the order of $30-50 \mathrm{~nm}$. While the majority of $\mathrm{Cu}$ migrates to the $\mathrm{Au}$ layer, there are also several $\mathrm{Cu}$-containing clusters located adjacent to the $\mathrm{ZnTe} \mid \mathrm{CdTe}$ interface. In Figure 5 there are two such clusters, one that appears at a GB and another at a defect. In addition, it is observed that $\mathrm{Zn}$ also accumulates in these $\mathrm{Cu}$ containing defect regions, and we will return to this observation below.

The elemental contour maps provide a qualitative overview of the changes induced by RTP. To provide a more quantitative perspective EDX line scans were used to quantify the elemental composition. Figure 6 displays an HAADF image as well as three plots showing the elemental profiles through the selected line scans. This TEM image was selected because it conveniently contains all the major features that have been observed along the $\mathrm{ZnTe} \mid \mathrm{CdTe}$ interface. The leftmost scan (b) profiles a clean interface with the absence of any major structural features. This is characteristic of the majority of the back contact region. The middle scan (c) shows the profile through a defect in the ZnTe layer, which were rarely observed. The final scan (d) profiles through the ZnTe layer and into a copper-rich inclusion within the CdTe.

The first elemental profile begins in the Pt layer deposited during FIB sample preparation and crosses the back contact in a line that is free of structural defects (Fig. 6b). The gold metallization layer remains largely intact, with little evidence of interdiffusion or rearrangement. It is observed that significant accumulation of $\mathrm{Cu}$ occurs at the $\mathrm{Au} \mid \mathrm{ZnTe}$ interface. This observation is consistent with the previous analysis of quantified SIMS results [10], which suggested that up to $80 \%$ of the $\mathrm{Cu}$ deposited in the $\mathrm{ZnTe}: \mathrm{Cu}$ layer segregates into the gold 

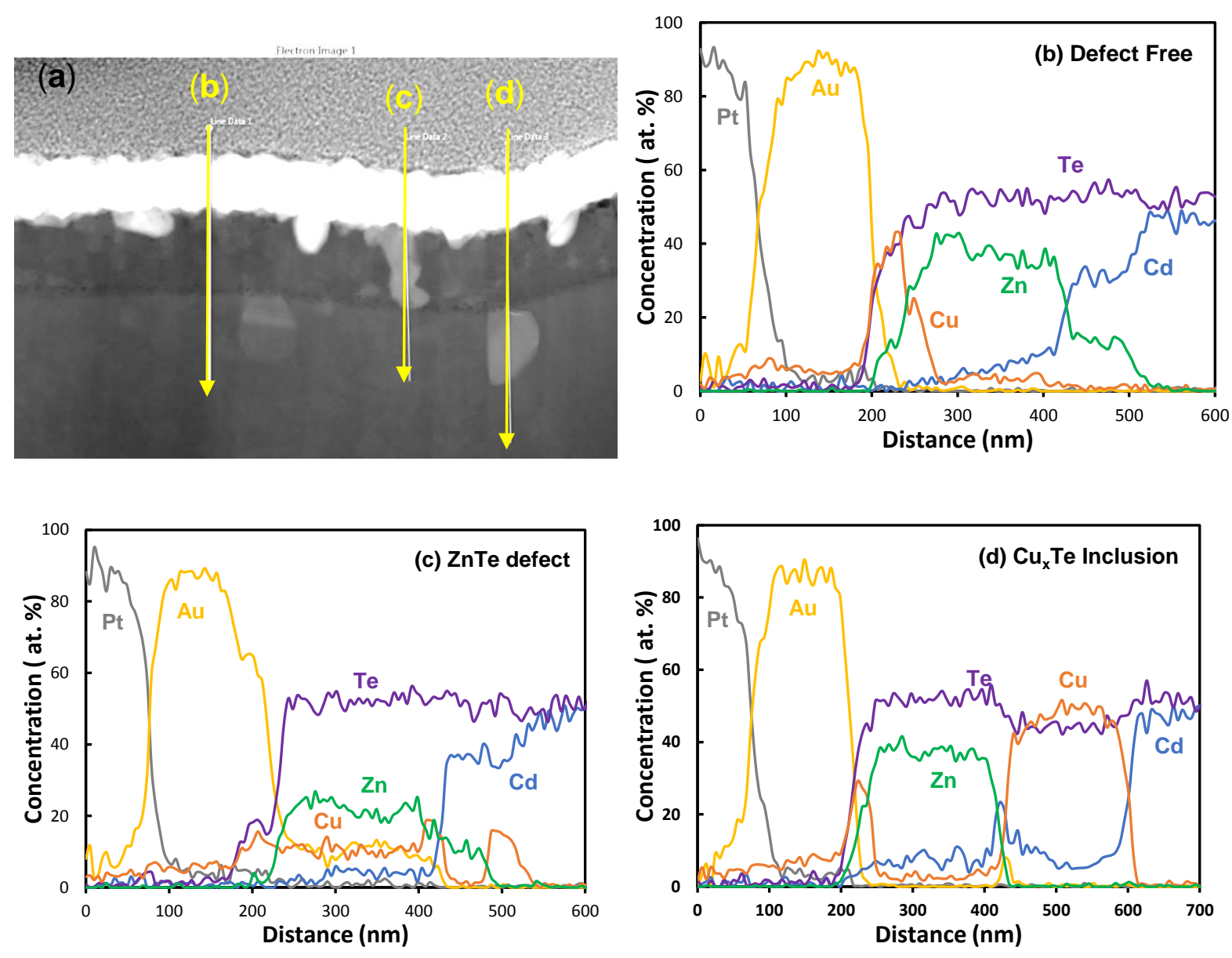

Figure 6. (a) TEM image of the back contact region after RTP and 1D elemental profiles through the highlighted regions that include (b) a defect-free region, (c) a region with a defect in the $\mathrm{ZnTe}$ layer, and (d) a region that passes through a $\mathrm{Cu}_{\mathrm{x}} \mathrm{Te}$ inclusion in the CdTe layer.

during RTP processing. This is perhaps unsurprising as these two metals are completely miscible. Now turning to the ZnTe layer we see two distinct regions that correspond to the morphological distinctions discussed above. It is observed that the composition of the first $\sim 100 \mathrm{~nm}$ of this layer adjacent to the gold is approximately stoichiometric ZnTe, corresponding to the region with well-defined crystallites (Fig. 3b). In contrast the last $50 \mathrm{~nm}$, the region that appears disordered in the TEM, shows evidence of extensive $\mathrm{Zn}-\mathrm{Cd}$ interdiffusion. In fact the $\mathrm{Cd}: \mathrm{Zn}$ ratio is approximately 2 in this region. This interdiffusion process appears to occur predominantly within 
the $\mathrm{ZnTe}$ layer, as the composition quickly reverts to stoichiometric $\mathrm{CdTe}$ once crossing the $\mathrm{ZnTe} \mid \mathrm{CdTe}$ interface.

The second line scan shows the profile through a defect present in the ZnTe layer (Fig. 6c). In this case it is observed that $\mathrm{Cu}$ does not accumulate at the Au|ZnTe interface but remains rather uniformly distributed and is accompanied by the infiltration of significant amounts of gold, both present at levels on the order of $\sim 10$ at. \% level throughout. Despite the presence of this structural defect there is again evidence of $\mathrm{Zn}$-Cd interdiffusion at the interface with CdTe. Finally, the third line scan (Fig. 6d) profiles through ZnTe into a Cu-rich cluster within the CdTe absorber. As in the first scan, it is observed that a significant amount of $\mathrm{Cu}$ accumulates at the $\mathrm{Au} \mid \mathrm{ZnTe}$ interface, but $\mathrm{Cu}$ is largely displaced from the $\mathrm{ZnTe}$ layer itself. Again strong evidence of $\mathrm{Cd}$ diffusion into the $\mathrm{ZnTe}$ layer is observed. As eluded to earlier, the composition of the $\mathrm{Cu}$ rich cluster appears to be $\mathrm{Cu}_{\mathrm{x}} \mathrm{Te}$, as the $\mathrm{Cd}$ signal is strongly attenuated and no other elements are detected. Upon exiting the cluster the composition abruptly returns to that of stoichiometric CdTe.

It is surmised that these $\mathrm{Cu}_{\mathrm{x}} \mathrm{Te}$ clusters located at defects and grain boundaries in the $\mathrm{CdTe}$ layer may have a major impact on both performance and stability, so their composition was investigated in more detail. Figure 7 displays the elemental line scans obtained across CdTe grain boundaries at the two positions highlighted in Figure 3. The first profile (Fig. 7a) crosses the small $\mathrm{Cu}_{\mathrm{x}} \mathrm{Te}$ cluster located within the CdTe grain boundary. No impurities are detected within the bulk CdTe. The cluster itself is composed exclusively of $\mathrm{Cu}$ and $\mathrm{Te}$, as the $\mathrm{Cd}$ signal is reduced to background levels. The approximate composition of the clusters is estimated to be $\mathrm{Cu}_{1.2} \mathrm{Te}$, which is very close to the $\mathrm{Cu}_{1.4} \mathrm{Te}$ phase that is commonly observed in CdTe back contacts.[14, 28, 29] Perhaps the most interesting aspect of this plot is the Zn profile. Recall that 
the elemental contour plots (Fig. 5) showed that the $\mathrm{Cu}$-rich aggregates within the $\mathrm{CdTe}$ were accompanied by enhanced levels of $\mathrm{Zn}$. The $1 \mathrm{D} \mathrm{Zn}$ profile shows that $\mathrm{Zn}$ is concentrated at the interface between the cluster and CdTe, giving rise to the idea that a thin layer of $\mathrm{Zn}$ may be encasing the $\mathrm{Cu}_{\mathrm{x}} \mathrm{Te}$ clusters.
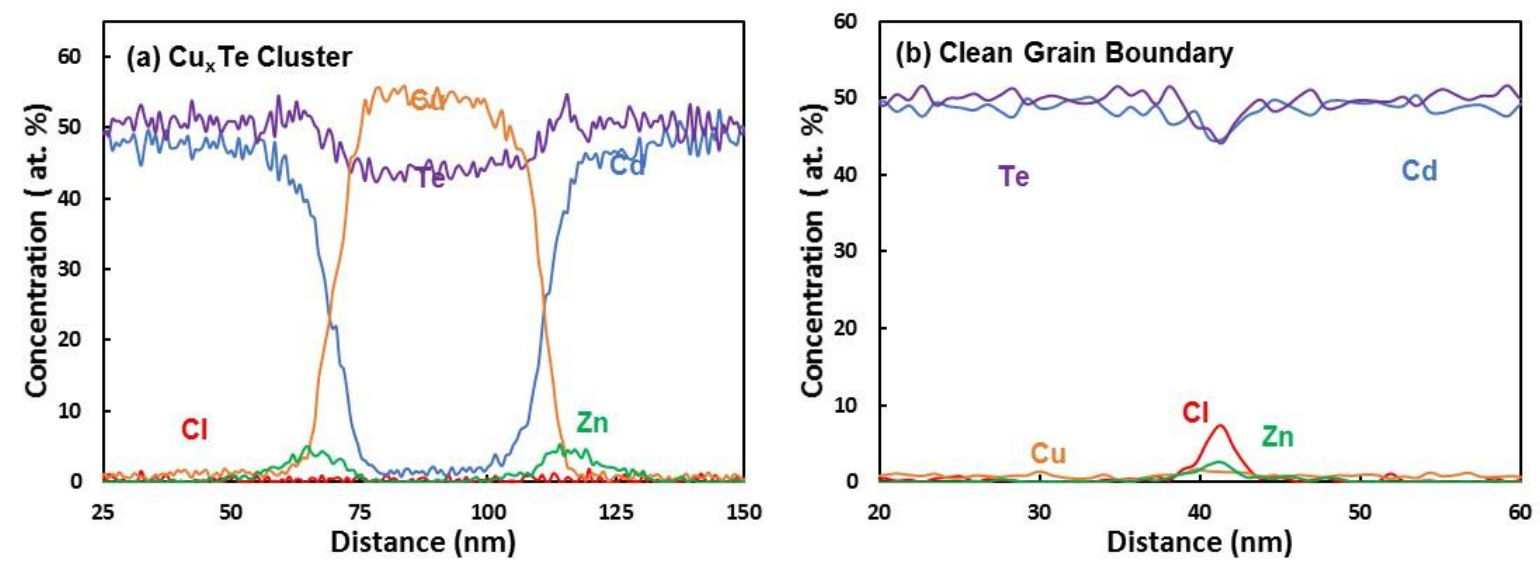

Figure 7. Elemental composition profiles across $\mathrm{CdTe}$ grain boundaries at the positions indicated in Fig. 3. Profile (a) crosses the small $\mathrm{Cu}_{\mathrm{x}} \mathrm{Te}$ inclusion and (b) crosses the clean grain boundary located $150 \mathrm{~nm}$ away.

Figure $7 \mathrm{~b}$ displays the elemental profile obtained across the clean grain boundary shown in Figure 3 that is approximately $150 \mathrm{~nm}$ away from the $\mathrm{Cu}_{1.4}$ Te cluster. The width of the grain boundary at this point is $\sim 2 \mathrm{~nm}$, and the only significant impurity observed is $\mathrm{Cl}$, which is wellknown to decorate grain boundaries in $\mathrm{CdTe}[18,23]$. The $\mathrm{Cl}$ reaches a peak concentration of $\sim 7$ at. \%, and is accompanied by a reduction in both $\mathrm{Cd}$ and $\mathrm{Te}$. There may also be a slight enrichment of $\mathrm{Zn}$ at this position. The $\mathrm{Cu}$ signal is at the limits of detection, with no significant difference in the nominal intensity between the grain and grain boundary. The grain boundary composition was examined at several positions in the sample, and no $\mathrm{Cu}$ or $\mathrm{Zn}$ was detected beyond $500 \mathrm{~nm}$ from the ZnTe interface, indicating that the structural and chemical changes induced by RTP were restricted to the vicinity of the back contact. 


\subsection{Atom Probe Tomography}

TEM analysis of the CSS absorbers suggests the formation of core-shell nanostructures comprised of $\mathrm{Zn}$ and $\mathrm{Cu}_{\mathrm{x}} \mathrm{Te}$ at GBs and defects in the CdTe near the back contact. To fully assess this possibility atom probe tomography was used to provide three-dimensional characterization of the back contact region using devices made at CSM by VTD. Previously we had used APT to examine the composition of the back contact region after RTP activation [10], and as reported here it was found that copper segregates and aggregates at both the interface with gold and CdTe. With the insight provided by the preceding TEM analysis we returned to these images to look for evidence of core-shell nanostructure formation.

Figure 8 shows 3D isoconcentrations of $\mathrm{Cu}$, and $\mathrm{Cu}$ and $\mathrm{Zn}$, with threshold levels set at 25 and 6 at. $\%$, respectively. The $\mathrm{Cu}$-rich clusters shown in this image range from 10 to $30 \mathrm{~nm}$ in diameter, and as in the TEM images they clusters were located in the CdTe absorber immediately adjacent to the $\mathrm{ZnTe}$ interface. The second image clearly shows that this $\mathrm{Cu}_{\mathrm{x}} \mathrm{Te}$ cluster in encased in Zn-rich shell. To further confirm the core-shell nature of these clusters Figure 9 shows $2 \mathrm{D}$ contour plots of the relative $\mathrm{Cu}$ and $\mathrm{Zn}$ densities extracted from a slice through the center of one of these clusters. The $\mathrm{Zn}$ composition reaches a peak of $\sim 12$ at $\%$ within the shell and the FWHM thickness of this layer is $\sim 11 \mathrm{~nm}$ based on 1D profiles orthogonal to the cluster surface. Both the width and density of $\mathrm{Zn}$ in the shell layer are in good agreement with the values provided by EDX line profiles shown in Fig. 7a. Quantitative analysis of the composition at the center of the particle confirms that its formula is $\mathrm{Cu}_{1.4} \mathrm{Te}$. In the mass spectrum there are peak overlaps between some isotopes of $\mathrm{Te}^{2+}$ and $\mathrm{Cu}^{+}$and $\mathrm{Te}^{2+}$ and $\mathrm{Zn}^{+}$. For quantification of the particle composition, the mass spectrum from only within the particle was extracted and 
analyzed. The APT analysis conditions were such that very little $\mathrm{Te}^{2+}$ was observed; nevertheless, peak decomposition was performed using the non-overlapping isotopes for precise quantification.

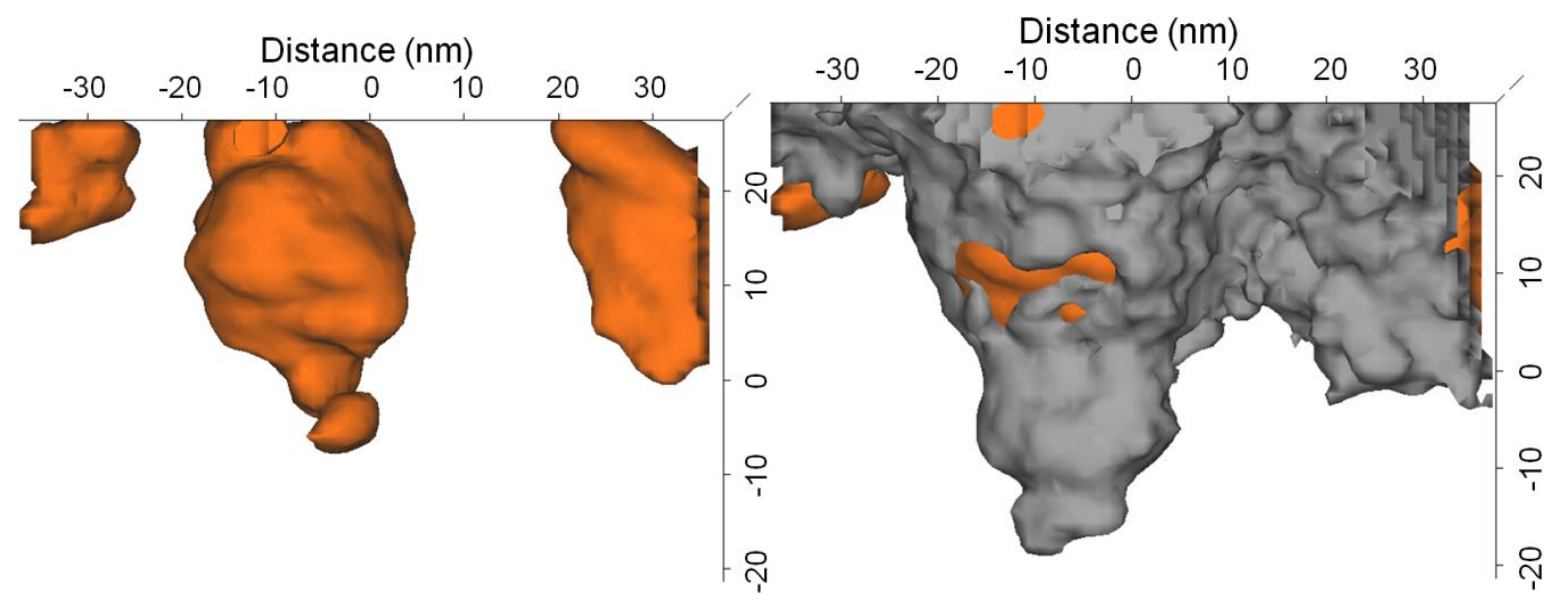

Figure 8. 3D isoconcentration surfaces of core-shell nanostructures in VTD CdTe provided by APT showing the (a) $\mathrm{Cu}$ and (b) both $\mathrm{Cu}$ and $\mathrm{Zn}$ with the concentration thresholds set at 25 and 6 at.\% respectively.

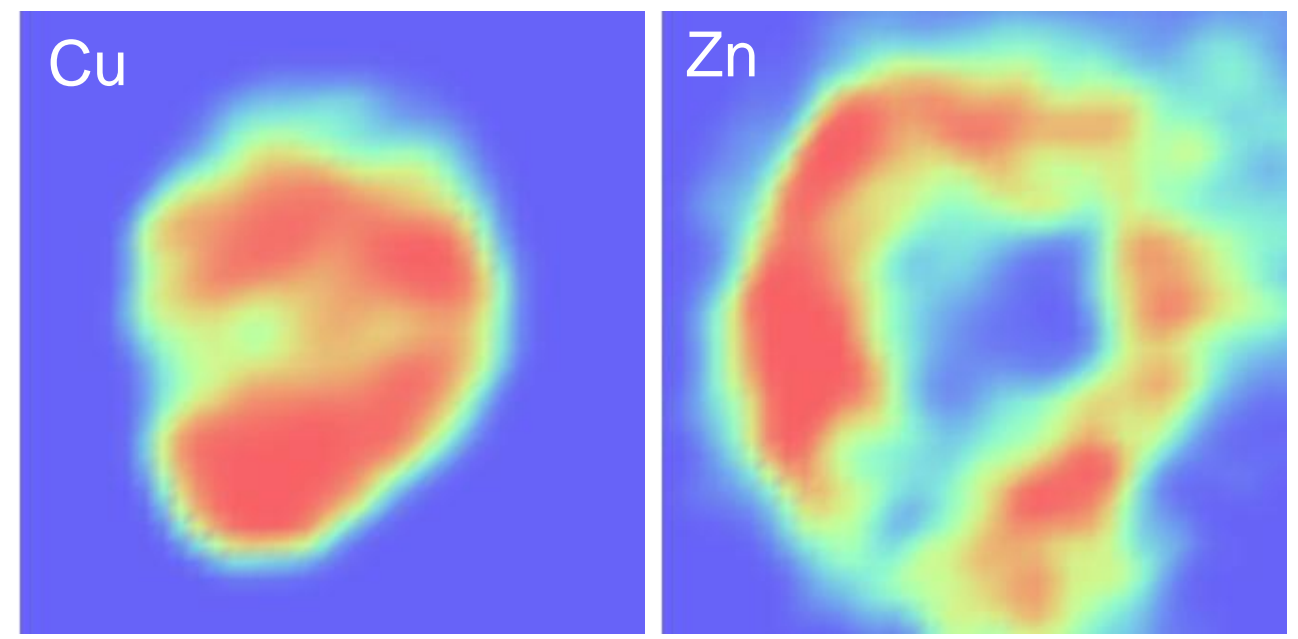

Figure 9. 2-D contour plots obtained from the center of a $\mathrm{Cu}_{1.4} \mathrm{Te}$ cluster confirming the coreshell structure with a $\mathrm{Zn}$-enriched layer completely encasing a $\mathrm{Cu}_{1.4} \mathrm{Te}$ cluster. 


\section{Discussion}

It is shown here that copper, introduced uniformly as $\mathrm{ZnTe} \mathrm{Cu}$ by co-evaporation, dramatically aggregates and segregates upon RTP activation. A majority of copper is found adjacent to the Au metallization layer, drawn here by the miscibility of the two metals. This $\mathrm{Cu}$ is effectively

removed from CdTe, explaining the limited amount observed in SIMS analysis [10]. The bulk of the remaining $\mathrm{Cu}$ is found in the form of $\mathrm{Cu}_{1.4} \mathrm{Te}$ clusters encased by a $\mathrm{Zn}$-enriched shell at grain boundaries and defects in CdTe near the interface with ZnTe. Such an observation is also consistent with the extremely low effective $\mathrm{Cu}$ diffusivity observed [10], as the transport of such nanoclusters would be significantly diminished relative to elemental $\mathrm{Cu}$. The sequestration of $\mathrm{Cu}$ at the metallization layer and in these clusters limits the amount of free $\mathrm{Cu}$ available to dope CdTe, explaining why the amounts of $\mathrm{Cu}$ used in $\mathrm{ZnTe}: \mathrm{Cu}$ buffers $[5,10,30]$ exceeds that employed in conventional $\mathrm{Cu}_{\mathrm{x}} \mathrm{Te}$ contacts $[14,15]$ or the amount required for optimal doping of CdTe [13].

The ZnTe layer itself undergoes significant rearrangement, forming a bilayer structure. Significant recrystallization and grain growth is observed in the layer adjacent to the $\mathrm{Au}$ metallization, with evidence of twin formation. The layer adjacent to CdTe appears disordered and is characterized by significant $\mathrm{Cd}-\mathrm{Zn}$ interdiffusion. It is suggested that the interdiffusion process liberates $\mathrm{Zn}$ and $\mathrm{Te}$, enabling the reaction with free $\mathrm{Cu}$ to form the $\mathrm{Zn}$-encased $\mathrm{Cu}_{1.4} \mathrm{Te}$ clusters. The great similarity of the nanostructured morphology observed in VTD and CSS devices suggests that this structure is a function of the RTP back contacting process and not the absorber itself. 
The phenomenological observations discussed above are also consistent with device performance. The significant characteristics of the $\mathrm{J}-\mathrm{V}$ curves obtained from $\mathrm{ZnTe}$ :Cu-contacted devices activated by RTP as shown in Figure 2 and previously [10,12] are the improvements to both $\mathrm{V}_{\mathrm{oc}}$ and FF. In particular, these devices exhibit low series resistance and the absence of rollover. It is suggested that CdTe-ZnTe interdiffusion passivates interface states, providing a good ohmic contact. It is well established that passivated GBs in CdTe provide pathways for efficient current collection [31]. The presence of $\mathrm{Cu}_{1.4} \mathrm{Te}$ clusters at the $\mathrm{GB}$ terminus are suggested to promote charge extraction. Rollover, often observed in devices contacted with $\mathrm{Cu}_{\mathrm{x}} \mathrm{Te}$ [19], has been attributed to the formation of Cu-related oxidation [14], and its absence in the devices described here suggest that ZnTe may mitigate its formation. Consistent with this hypothesis oxygen was not detected above background levels anywhere within the back contact region by either APT or EDX. The diffusion of excess $\mathrm{Cu}$ into the $\mathrm{CdS}$ often manifests itself in a "cross over" feature when comparing dark and light J-V curves [14]. Likewise excess $\mathrm{Cu}$ in the absorber itself has been correlated with voltage-dependent collection, which limits FF. Both of these issues are concerns for long term stability. The absence of significant cross-over and high FF in the ZnTe:Cu contacted devices suggests that excess $\mathrm{Cu}$ diffusion is mitigated, likely through its sequestration in clusters as described above.

It is of value to compare the results observed here for $\mathrm{ZnTe:Cu}$ with the more commonly used $\mathrm{Cu}_{\mathrm{x}} \mathrm{Te}$ buffer layer $[32,33]$. The $\mathrm{Cu}_{\mathrm{x}} \mathrm{Te}$ buffer is typically prepared by etching the $\mathrm{CdTe}$ absorber to remove oxides and create a Te-rich interface, followed by evaporation of copper and thermal annealing. The $\mathrm{Cu}$-Te phase diagram is incredibly complex with numerous phases and polymorphs, particularly in the $\mathrm{Cu}_{2-\mathrm{x}} \mathrm{Te}$ region [34]. Nevertheless, under conditions employed for forming CdTe back contacts the three primary phases that have been observed are $\mathrm{CuTe}, \mathrm{Cu}_{1.4} \mathrm{Te}$, 
and $\mathrm{Cu}_{2} \mathrm{Te}$, which may be controlled through the amount of $\mathrm{Cu}$ supplied and/or the temperature used for activation [28]. Early reports [33] suggested that $\mathrm{Cu}_{2} \mathrm{Te}$ was optimal for cell performance, being the most highly conductive phase it provides low series resistance. However, $\mathrm{Cu}_{2} \mathrm{Te}$ has a high propensity to decompose and release $\mathrm{Cu}$ [27], raising stability concerns. $\mathrm{Wu}$ and co-workers reported best performance with a mixture of $\mathrm{CuTe}$ and $\mathrm{Cu}_{1.4} \mathrm{Te}$ [14], recommending $\mathrm{x} \leq 1.4$ to minimize excess $\mathrm{Cu}$ diffusion. More recently it was reported that $\mathrm{Cu}_{1.4} \mathrm{Te}$ contacts exhibited improved stability under thermal cycling than devices employing mixed $\mathrm{Cu}_{1.4} \mathrm{Te} / \mathrm{CuTe}$ contacts [29]. Thus there is an emerging consensus that the $\mathrm{Cu}_{1.4} \mathrm{Te}$ phase provides an ideal balance of conductivity and stability. As in the case of $\mathrm{Cu}_{\mathrm{x}} \mathrm{Te}$, there is an optimum amount of $\mathrm{Cu}$ that produces best performance in devices contacted with $\mathrm{ZnTe}: \mathrm{Cu}$ [11]. In the optimal devices analyzed here the $\mathrm{Cu}_{1.4}$ Te phase is observed to form, consistent with the findings from work using $\mathrm{Cu}_{\mathrm{x}}$ Te buffer layers.

\section{Conclusions}

Nanoscale imaging and analysis has provided new insight into the role of $\mathrm{ZnTe}$ buffer layers on CdTe device performance and stability. It is shown that significant CdTe-ZnTe interdiffusion occurs during thermal activation, creating a graded interface. Copper reacts with $\mathrm{Zn}$ and Te released during this process, forming $\mathrm{Zn}$-encased $\mathrm{Cu}_{1.4} \mathrm{Te}$ core-shell nanostructures that are found in CdTe at grain boundaries and defects along the interface with ZnTe. It is suggested that these processes passivate defects and produce a good ohmic contact that enable the good $\mathrm{V}_{\mathrm{oc}}$ and FF observed in these devices. The absence of rollover in these devices is attributed to the ability of this contact to minimize the formation of $\mathrm{Cu}$-related oxides. The sequestration of $\mathrm{Cu}$ into 
nanoclusters is proposed as a mechanism to limit its diffusion into the $\mathrm{CdTe}$ and $\mathrm{CdS}$, with positive implications for long term device stability.

\section{Acknowledgements}

CAW, JL, DRD, TRO, and JDB gratefully acknowledge the Bay Area Photovoltaic Consortium for their support of this work under Department of Energy Award number DE-EE0004946. AA and JMW was funded by UKERC through the EPSRC Supergen SuperSolar Hub. DMM and TMB were was supported by the U.S. Department of Energy through the SunShot Foundational Program to Advance Cell Efficiency (F-PACE) under Contract No. DE-AC36-08-GO28308.

\section{References}

[1] M. A. Green, K. Emery, Y. Hishikawa, W. Warta, E. D. Dunlop, Solar cell efficiency tables (version 46), Prog. Photovolt.: Res. Appl. 23 (2015), 805-812.

[2] M. Gloeckler, I. Sankin, Z. Zhao, CdTe Solar Cells at the Threshold to 20\% Efficiency, IEEE J. Photovolt. 3 (2013), 1389-1393.

[3] A. Niemegeers, M. Burgelman, Effects of the Au/CdTe back contact on IV and CV characteristics of Au/CdTe/CdS/TCO solar cells, J. Appl. Phys. 81 (1997), 2881-2886.

[4] A. L. Fahrenbruch, Exploring back contact technology to increase CdS/CdTe solar cell efficiency, Mater. Res. Soc. Symp. Proc. 1012 (2007), 283-290.

[5] T. A. Gessert, A. R. Mason, P. Sheldon, A. B. Swartzlander, D. Niles, T. J. Coutts, Development of $\mathrm{Cu}$-doped $\mathrm{ZnTe}$ as a back-contact interface layer for thin-film CdS/CdTe solar cells, J. Vac. Sci. Technol. A 14 (1996), 806. 
[6] B. E. McCandless, K. D. Dobson, Processing options for CdTe thin film solar cells, Solar Energy 77 (2004), 839-856.

[7] C. W. Warren, J. Li, C. A. Wolden, D. M. Meysing, T. M. Barnes, D. W. Miller, J. T. Heath, M. C. Lonergan, The effect of copper on the sub-bandgap density of states of CdTe solar cells, Appl. Phys. Lett. 106 (2015), 203903.

[8] S. H. Demtsu, D. S. Albin, J. R. Sites, W. K. Metzger, A. Duda, Cu-related recombination in CdS/CdTe solar cells, Thin Solid Films 516 (2008), 2251-2254.

[9] N. Strevel, L. Trippel, C. Kotarba, I. Khan, Improvements in CdTe module reliability and long-term degradation through advances in construction and device innovation, Photovolt. Int. 22 (2014), 66-74.

[10] J. Li, D. R. Diercks, T. R. Ohno, C. W. Warren, M. C. Lonergan, J. D. Beach, C. A. Wolden, Controlled activation of $\mathrm{ZnTe}: \mathrm{Cu}$ contacted CdTe solar cells using rapid thermal processing, Solar Energy Mater. Solar Cells 133 (2015), 208-215.

[11] J. Li, J. D. Beach, C. A. Wolden, "Rapid thermal processing of ZnTe:Cu contacted CdTe solar cells," in $40^{\text {th }}$ IEEE Photovoltaic Specialists Conference, Denver, CO, 2014, pp. 2360-2365.

[12] H. P. Mahabaduge, W. L. Rance, J. M. Burst, M. O. Reese, D. M. Meysing, C. A. Wolden, J. Li, J. D. Beach, T. A. Gessert, W. K. Metzger, S. Garner, T. M. Barnes, Highefficiency, flexible CdTe solar cells on ultra-thin glass substrates, Appl. Phys. Lett. 106 (2015), 133501.

[13] L. Kranz, C. Gretener, J. Perrenoud, R. Schmitt, F. Pianezzi, F. La Mattina, P. Blösch, E. Cheah, A. Chirilă, C. M. Fella, H. Hagendorfer, T. Jäger, S. Nishiwaki, A. R. Uhl, S. 
Buecheler, A. N. Tiwari, Doping of polycrystalline CdTe for high-efficiency solar cells on flexible metal foil, Nat. Commun. 4 (2013), 2306.

[14] X. Wu, J. Zhou, A. Duda, Y. Yan, G. Teeter, S. Asher, W. K. Metzger, S. Demtsu, S.-H. Wei, R. Noufi, Phase control of $\mathrm{Cu}_{\mathrm{x}} \mathrm{Te}$ film and its effects on $\mathrm{CdS} / \mathrm{CdTe}$ solar cell, Thin Solid Films 515 (2007), 5798-5803.

[15] S. S. Hegedus, B. E. McCandless, CdTe contacts for CdTe/CdS solar cells: effect of $\mathrm{Cu}$ thickness, surface preparation and recontacting on device performance and stability, Solar Energy Mater. Solar Cells 88 (2005), 75-95.

[16] E. D. Jones, N. M. Stewart, J. B. Mullin, The diffusion of copper in cadmium telluride, J. Cryst. Growth 117 (1992), 244-248.

[17] H. H. Woodbury, M. Aven, Some diffusion and solubility measurements of Cu in CdTe, J. Appl. Phys. 39 (1968), 5485-5487.

[18] L. Kranz, C. Gretener, J. Perrenoud, D. Jaeger, S. S. A. Gerstl, R. Schmitt, S. Buecheler, A. N. Tiwari, Tailoring impurity distribution in polycrystalline CdTe solar cells for enhanced minority carrier lifetime, Adv. Energy Mater. 4 (2014).

[19] D. M. Meysing, C. A. Wolden, M. M. Griffith, H. Mahabaduge, J. Pankow, M. O. Reese, J. M. Burst, W. L. Rance, T. M. Barnes, Properties of reactively sputtered oxygenated cadmium sulfide (CdS:O) and their impact on CdTe solar cell performance, J. Vac. Sci.Technol. A 33 (2015), 021203.

[20] J. M. Kestner, S. McElvain, S. Kelly, L. M. Woods, T. R. Ohno, C. A. Wolden, An experimental and modeling analysis of vapor transport deposition of cadmium telluride, Solar Energy Mater. Solar Cells 83 (2004), 55-65 
[21] Y. Yan, D. Albin, M. M. Al-Jassim, Do grain boundaries assist S diffusion in polycrystalline CdS/CdTe heterojunctions?, Appl. Phys. Lett. 78 (2001), 171-173.

[22] D. S. Albin, Y. Yan, M. M. Al-Jassim, The effect of oxygen on interface microstructure evolution in CdS/CdTe solar cells, Prog. Photovolt.: Res. Appl. 10 (2002), 309-322.

[23] A. Abbas, G. D. West, J. W. Bowers, P. M. Kaminski, B. Maniscalco, J. M. Walls, K. L. Barth, W. S. Sampath, "Cadmium chloride assisted re-crystallization of CdTe: The effect of annealing over-treatment," in 40th IEEE Photovoltaic Specialist Conference, 2014, pp. 0701-0706.

[24] D. R. Diercks, J. Li, J. D. Beach, C. A. Wolden, B. P. Gorman, "Atom probe tomography for nanoscale characterization of CdTe device absorber layers and interfaces," in $40^{\text {th }}$ IEEE Photovoltaic Specialists Conference, 2014, pp. 0085-0089.

[25] B. Gorman, D. Diercks, N. Salmon, E. Stach, G. Amador, C. Hartfield, Hardware and techniques for cross-correlative TEM and atom probe analysis, Microsc. Today 16 (2008), 42-47.

[26] A. Abbas, D. M. Meysing, J. Li, J. D. Beach, T. M. Barnes, J. M. Walls, C. A. Wolden, "Structural and Chemical Characterization of the Back Contact Region in High Efficiency CdTe Solar Cells," in $42^{\text {nd }}$ IEEE Photovoltaic Specialists Conference, New Orleans, 2015, p. Paper \#952.

[27] G. Teeter, $\mathrm{Cu}_{2}$ Te synthesis and in-vacuum thermal decomposition: Chemical-kinetics analysis and comparison to equilibrium vapor-pressure measurements, Thin Solid Films 515 (2007), 7886-7891. 
[28] J. Zhou, X. Wu, A. Duda, G. Teeter, S. H. Demtsu, The formation of different phases of $\mathrm{Cu}_{\mathrm{x}} \mathrm{Te}$ and their effects on CdTe/CdS solar cells, Thin Solid Films 515 (2007), 73647369.

[29] G. Luo, B. Lv, W. Li, L. Feng, J. Zhang, L. Wu, G. Zeng, Characterization of $\mathrm{Cu}_{1.4} \mathrm{Te}$ Thin Films for CdTe Solar Cells, Int. J. Photoenergy 2014 (2014), 5.

[30] T. A. Gessert, W. K. Metzger, P. Dippo, S. E. Asher, R. G. Dhere, M. R. Young, Dependence of carrier lifetime on $\mathrm{Cu}$-contacting temperature and $\mathrm{ZnTe}: \mathrm{Cu}$ thickness in CdS/CdTe thin film solar cells, Thin Solid Films 517 (2009), 2370-2373.

[31] J. D. Poplawsky, N. R. Paudel, C. Li, C. M. Parish, D. Leonard, Y. F. Yan, S. J. Pennycook, Direct Imaging of Cl- and Cu-Induced Short-Circuit Efficiency Changes in CdTe Solar Cells, Adv. Energy Mater. 4 (2014), 8.

[32] C. S. Ferekides, D. Marinskiy, V. Viswanathan, B. Tetali, V. Palekis, P. Selvaraj, D. L. Morel, High efficiency CSS CdTe solar cells, Thin Solid Films 361-362 (2000), 520-526.

[33] B. E. McCandless, S. S. Hegedus, R. W. Birkmire, D. Cunningham, Correlation of surface phases with electrical behavior in thin-film CdTe devices, Thin Solid Films 431 (2003), 249-256.

[34] A. S. Pashinkin, V. A. Fedorov, Phase equilibria in the Cu-Te system, Inorg. Mater. 39 (2003), 539-554. 

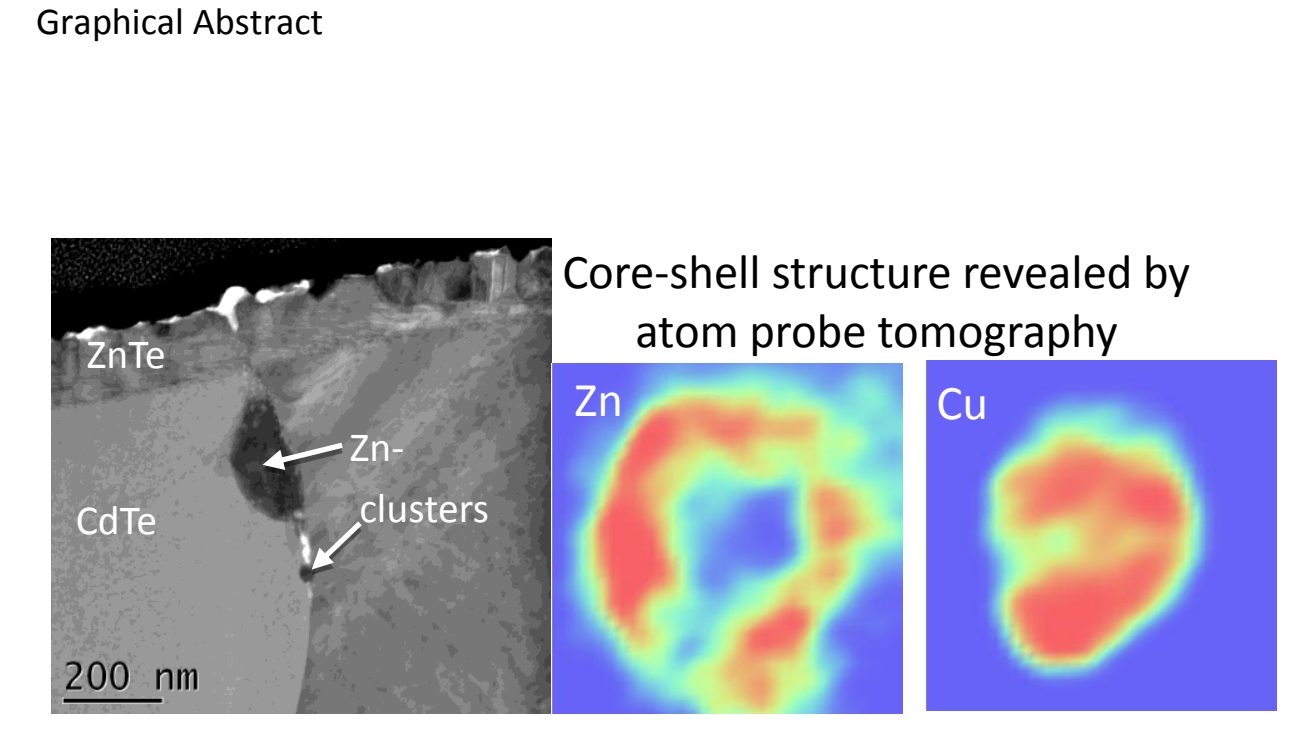

Graphical Abstract 